\title{
Espacialização da cobertura do serviço de saneamento básico e do índice de desenvolvimento humano dos municípios do Marajó, Pará
}

\section{Spatialization of service coverage of sanitation basic and of human development index of municipalities the Marajó, Pará}

\author{
Diêgo Lima Crispim ${ }^{1}$, Rodrigo Silvano Silva Rodrigues ${ }^{2}$, Artur Sales de Abreu Vieira ${ }^{3}$, Rafaela Nazareth Pinheiro de Oliveira \\ Silveira ${ }^{4}$, Lindemberg Lima Fernandes ${ }^{5}$
}

\begin{abstract}
Resumo: O acesso aos serviços de saneamento básico tem causado preocupação, principalmente nos estados das regiões Norte e Nordeste e, mais especificamente em municípios com orçamento limitado, de pequeno porte e distante das capitais, onde abrigam populações em situações de vulnerabilidade social. Neste contexto, objetivou-se analisar a situação de alguns serviços do saneamento ambiental e do índice de desenvolvimento humano municipal dos municípios da mesorregião geográfica do Marajó, estado do Pará. Para tanto, foi levantado algumas informações por meio de dados secundários dos municípios que compõe a mesorregião em estudo, com ênfase em alguns serviços de saneamento e do IDHM. Os resultados demonstraram que o índice de atendimento do serviço de coleta de esgoto doméstico deixa extremamente a desejar, em particular com relação à coleta e ao tratamento do esgoto sanitário. Quanto à forma de destinação dos resíduos sólidos, verificou-se que alguns municípios ainda adotam uma maneira inapropriada, depositando-os em lixões a céu aberto. A disponibilidade de informações nessas bases de dados dos órgãos e entidades é fundamental para auxiliar na determinação de prioridades nas ações do poder público e da sociedade civil em relação aos serviços de saneamento.
\end{abstract}

Palavras-chave: Abastecimento de água. Resíduos sólidos. Coleta de esgoto.

\begin{abstract}
The Access to basic sanitation services has caused concern, particularly in the states of North and Northeast regions, and more specifically in municipalities with limited budget, of small size and distant from the capital, where they are located populations in vulnerable social situations. In this context, the aim of this research was to analyze the situation of some services of environmental sanitation and the index of development human municipal of municipalities the mesoregion of Marajó, state of Pará. For that was lifted up some information through secondary data of the municipalities that make up the region under study, with an emphasis on some sanitation and IDHM services. The results showed that the coverage rate of the sewage collection serviceleaves extremely to be desired, particularly regarding the collection and treatment of sewage. How much the destination of solid waste, it was found that some municipalities adopt an inappropriate manner, depositing them in open dumps. The availability of information in the databases of agencies and entities is critical to assist in determining priorities in the actions of government and civil society in relation to sanitation services.
\end{abstract}

Key words: Supply of water. Waste solid. Collectingt of Sewage.

\footnotetext{
*Autor para correspondência

Recebido para publicação em 27/08/2016; aprovado em 15/10/2016

${ }^{1}$ Graduação em Engenharia Ambiental (UFCG); Especialista em Educação Ambiental e Geografia do Semiárido (IFRN); Mestre em Gestão e Tecnologia Ambiental em Sistemas Agroindustriais (UFCG); Doutorando em Engenharia Civil (UFPA). E-mail: diegolc_85@hotmail.com

${ }^{2}$ Graduação em Engenharia sanitária e Ambiental (UFPA); Mestrando no Programa de Pós-graduação em Engenharia Civil (UFPA). E-mail: rssr@ ufpa.br

${ }^{3}$ Graduação em Engenharia Sanitária e Ambiental (UFPA); Mestrando no Programa de Pós-graduação em Engenharia Civil (UFPA). E-mail: asales@hotmail.com

${ }^{4}$ Graduação em Engenharia Civil; Mestra em Geotecnia (UNB); Doutorando em Engenharia Civil (UFPA). E-mail: rafaelanpos@ gmail.com

${ }^{5}$ Engenheiro civil, Doutor em Desenvolvimento Sustentável do Trópico Úmido, Professor da faculdade de Engenharia Sanitária e Ambiental e da Pósgraduação em Engenharia Civil da Universidade Federal do Pará. E-mail: lberge@ufpa.br
} 


\section{INTRODUÇÃO}

Avanços científicos e tecnológicos quanto à saúde pública têm impulsionado intervenções de maneira consistente para reduzir drasticamente os números expostos a riscos de emanações tóxicas, infecciosas e físicas nos compartimentos ambientais fundamentais do ar, solo e água, e através da cadeia alimentar (REIS et al., 2015). O ponto de partida para otimização da gestão dos serviços públicos, sobretudo de saúde e saneamento, se dá em conhecer a situação atual enfrentada pela população, relacionando os aspectos socioeconômicos e a infraestrutura local. Formulações de estratégias para o desenvolvimento de infraestruturas direcionadas para promover melhor acessibilidade aos cuidados de saúde devem ser concebidas com base nas necessidades e anseios das pessoas, isso pode melhorar a utilização dos serviços de saúde pública nos países em desenvolvimento (JANA; HARATA, 2016). A definição da qualidade de vida aborda o nível de prazer, conforto e saúde, no entanto, este conceito tem uma grande variedade de contextos, incluindo o bem-estar das sociedades (EBRAHIMZADEH et al., 2016).

A infraestrutura urbana, de acordo com Ferrer et al. (2016), é um conceito multifacetado, e vai além de um conjunto de instalações de engenharia, utilitários e sistemas, sendo um espaço para a governança local, atrelado às questões do crescimento econômico, alterações climáticas, e de resíduos urbanos. Projetos de infraestrutura tradicionais datam de cidades da antiguidade, e incluem estradas e rodovias, redes elétricas e sistemas de que o transporte ou tratamento de água potável, esgoto e águas pluviais (LI et al., 2016).

Um dos componentes fundamentais na infraestrutura de uma localidade é o saneamento básico. Esse serviço é indispensável para a saúde humana e para o meio ambiente. Entretanto, os serviços de saneamento básico não consegue acompanhar o ritmo do crescimento populacional e o desenvolvimento desordenado dos ambientes urbanos. Essa situação tem contribuído para geração de distorções no uso do espaço urbano, ocasionando o surgimento de aglomerações sem as condições mínimas de qualidade de vida para a população. Ebrahimzadeh et al. (2016) ressalta que a inclusão dos indicadores de qualidade de vida no processo de planejamento urbano dará melhores resultados na funcionalidade urbana, com mais infraestrutura e serviços, tornando as cidades mais atraentes.

Como o processo de urbanização possui natureza pública, o Estado fica na incumbência como agente regulador, fiscalizador e o principal idealizador de políticas públicas. Esse último elemento ganhou destaque na ordem constitucional vigente, uma vez que está previsto na Carta Magna que a Administração Pública é encarregada pela política urbana. A questão do urbanismo tem instigado muitas discussões e estudos direcionados à solução dos relevantes problemas encarados pelas cidades, proveniente de um gerenciamento inapropriado e de serviços inadequados, gerando externalidades negativas sobre o meio ambiente (CRISPIM et al., 2014).

Ressalta-se que a problemática que envolve o saneamento básico é um tema relevante no atual cenário da região do arquipélago do Marajó por está ligado diretamente à qualidade de vida da população, tendo como discussões imprescindíveis à disponibilidade de rede de esgoto, rede de abastecimento de água, coleta e destinação de resíduos sólidos. Desta forma, a expansão e o fortalecimento da infraestrutura do saneamento ambiental, com apropriada gestão e articulações no campo social e político, constituem uma importante condição para convivência na região, servindo como componente básico para interiorização do desenvolvimento e melhoria na qualidade de vida dos habitantes dessas localidades.

Pelo exposto, entende-se que a relevância da discussão a respeito da situação do acesso da população aos serviços supracitados nos municípios da mesorregião do Marajó, pode possibilitar a construção do conhecimento a respeito da realidade da cobertura dos serviços de saneamento e do desempenho de cada município em relação ao IDHM, como também pode colaborar na adequação da gestão e elaboração de projetos que possam fortalecer os serviços de infraestrutura urbana, que nem sempre consegue acompanhar o crescimento urbano, e consequentemente, atender a população. Neste contexto, objetivou-se espacializar a situação do IDHM e a cobertura dos serviços de infraestrutura sanitária dos municípios do Arquipélago do Marajó, estado do Pará.

\section{MATERIAL E MÉTODOS}

\section{Caracterização da pesquisa}

A ordem de classificação da pesquisa realizada neste estudo quanto à sua natureza é aplicada, no qual objetiva-se gerar conhecimentos para aplicação prática direcionada à solução de problemas peculiares de um determinado local. Quanto aos seus objetivos constitui-se em uma pesquisa exploratória, e em relação aos procedimentos técnicos enquadra-se em uma pesquisa bibliográfica e documental (PRODANOV; FREITAS, 2013).

A pesquisa iniciou-se com uma investigação exploratória, a partir de material que versa a respeito da temática de estudo, objetivando-se possibilitar maior familiaridade com o problema e a área pesquisada. Posteriormente à etapa da pesquisa bibliográfica e documental, procedeu-se à escolha do lugar para realização da pesquisa. A escala espacial da pesquisa abrangeu os municípios da mesorregião do Marajó-PA. Justifica-se a escolha destes municípios em razão da ausência de trabalhos acadêmicos direcionados às características do saneamento básico e do índice do desenvolvimento humano municipal (IDHM).

Para essa pesquisa foram escolhidos componentes do contexto demográfico, do saneamento ambiental e dados do IDHM, a fim de avaliar a situação desses municípios com base na disponibilidade de dados (censos, institutos, agências, dentre outros). Deste modo, foram utilizados dados secundários das seguintes fontes: Instituto Brasileiro de Geografia e Estatística (IBGE), Programa das Nações Unidas para o Desenvolvimento (PNUD) e o Sistema Nacional de Informações sobre Saneamento (SNIS). Para elaboração dos mapas temáticos foi utilizado o software livre gvSIG 1.12, no qual foram utilizadas shapefiles disponibilizadas pelo Instituto Brasileiro de Geografia e Estatística (IBGE). Além disso, as informações vetoriais foram padronizadas em uma mesma projeção geográfica, sendo estabelecida para esse trabalho a projeção: EPSG: 31982 Sirgas 2000/UTM Zones $22 \mathrm{~S}$. 


\section{Caracterização da área de estudo}

A área de abrangência da pesquisa compreende os dezesseis municípios que integram a mesorregião geográfica do Marajó (Figura 1), localizado no estado do Pará. Essa mesorregião é composta pelas microrregiões geográficas do Arari, Furos de Breves e Portel, sendo que as duas primeiras microrregiões abrangem muncípios inseridos completamante no Arquipélago do Marajó, enquanto, que a microrregião de Breves compreende municípios com sedes em territorios continentais, na parte sul/sudoeste da mesorregião. O agrupamento dessas microrregiões compreende uma área de 104.108,40 km² (NASCIMENTO et al., 2016; IBGE, 2010).

Figura 1. Mapa de localização dos municípios Arquipélago do Marajó, estado do Pará.

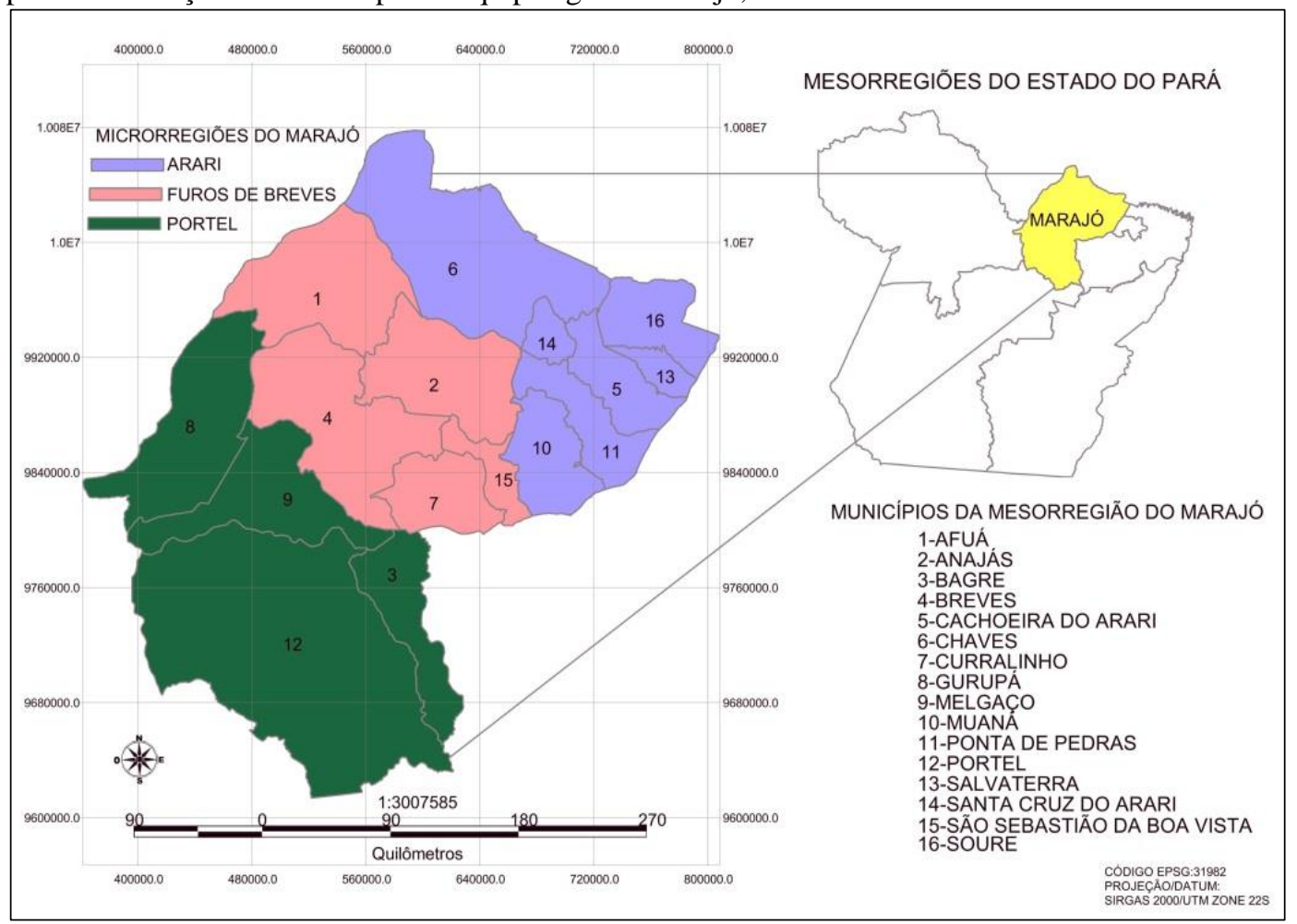

Fonte: Autores (2016).

De acordo com a classificação de Köppen-Geiger, o clima da região do Marajó é dividido em dois subgrupos, no qual o primeiro é o Af (clima equatorial sempre úmido) na parte ocidental, não apresentando estação seca, com abundantes chuvas estacionais, com precipitação pluviométrica média anual de $2.900 \mathrm{~mm}$ e a mensal geralmente superior a $60 \mathrm{~mm}$. Enquanto, que a parte oriental é caracterizada pelo subgrupo Am (clima equatorial monçônico), no qual o regime pluviométrico anual define um período moderamente seco, contudo o total de chuva é suficiente para suportar este período, a pluviosidade média anual é de aproximadamente $2.100 \mathrm{~mm}$ e mensal inferior a 60 mm durante mais de dois meses do ano (BEZERRA, 2014; LIMA, 2008). A temperatura média do mês mais frio é maior que $20^{\circ} \mathrm{C}$ e a temperatura média anual fica entre 26 a $27{ }^{\circ} \mathrm{C}$, a umidade relativa do ar é maior que 80\% (BEZERRA, 2014; MDA, 2012).

A hidrografia da região é formada por uma enredada rede de drenagem de canais recentes, tais como: paleocanais, furos, baías, paranás, meandros abandonados, lagos e igarapés, estabelecendo um complexo em evolução, no qual se destacam os rios Amazonas, Pará, Anapu, Jacundá e Anajás, com seus numerosos afluentes. A hidrografia da região desempenha um importante papel, pois é o único meio de transporte e comunicação entre as cidades e vilas. Além disso, dispõe de um potencial pesqueiro, e funciona como um fomentador sedimentar das várzeas, por meio da ação dos rios de água barrenta (BEZERRA, 2014; MDA, 2012; BRASIL, 2007).

O relevo da região do Marajó é caracterizado por uma brusca interrupção da planície de aluviões holocênicas da calha do Amazonas, abaixo da embocadura do Xingu (BEZERRA, 2014). Com relação aos tipos de solos predominantes na área de estudo, destaque-se os hidromórficos do tipo Glei húmico e pouco húmicos, decorrentes do acúmulo de sedimentos recentes do quaternário, no qual foram transportados e depositados nessas áreas, pelas inundações frequentes dos rios de água barrenta, como o Amazonas. (LIMA, 2008; LOURENÇO JUNIOR; GRACIA, 2008). Esses tipos de solos possuem horizonte superficial de aproximadamente 25 a $30 \mathrm{~cm}$, com elevada porcentagem de matéria orgânica, por cima da camada mineral proveniente do material sedimentar.

A formação geológica estratigráfica da região do Marajó corresponde ao período quaternário, sendo constituída pela unidade de aluviões. Estes são coberturas formadas por materiais erodidos ou sedimentados, retrabalhados e carreados pelos fluxos de água nos canais naturais em seus leitos e margens. A formação geológica local é constituída pelo Arco de Gurupá, que se expande entre os Cratons Guianês e Guaporé e sob a ilha grande de Gurupá (BRASIL, 1974). 


\section{Dados demográficos e econômicos}

Com base em informações do último censo demográfico (IBGE, 2010), a população total dos municípios que compõem a Mesorregião do Marajó no ano de 2010 foi de 487.010 habitantes, com uma população urbana de 211.452 hab. e a rural de 275.558 habitantes. Enquanto, que a população estimada para o ano de 2016 é de 541.175 habitantes, com uma densidade demográfica neste ano de 5,20 $\left(\mathrm{hab} / \mathrm{km}^{2}\right.$ ), para uma área de unidade territorial de 104.108,40 $\mathrm{km}^{2}$. A taxa de urbanização da região do Marajó é inferior a da região Norte, em que no ano de 2010 foi de 73,53\%, onde aproximadamente $56,58 \%$ da população local moram nas áreas rurais, ao mesmo tempo em que a média do país é de
15,4\% (Tabela 1). A determinação da taxa de urbanização é realizada por meio da percentagem de população (Equação 1) que vive nas cidades em relação à população total do território (IBGE, 2010).

$$
\mathrm{TU}=\mathrm{PU} / \mathrm{PA} .1000
$$

Em que: TU é a taxa de urbanização; PU é a população urbana; PA é a população absoluta (total).

Embora a região apresente uma considerável emigração, a mesma permanece crescendo, por causa das elevadas taxas de fertilidade e de natalidade (BRASIL, 2007).

Tabela 1 - Indicadores demográficos, população urbana, rural e taxa de urbanização dos municípios do Arquipélago do Marajó, estado do Pará.

\begin{tabular}{cccccccc}
\hline Municípios & $\mathbf{1}$ & $\mathbf{2}$ & $\mathbf{3}$ & $\mathbf{4}$ & $\mathbf{5}$ & $\mathbf{6}$ \\
\hline Afuá & 35.042 & 37.788 & $8.372,80$ & 4,51 & 9.478 & 25.564 \\
Anajás & 24.759 & 28.012 & $6.912,53$ & 4,05 & 9.494 & 15.265 & 38,3 \\
Bagre & 23.864 & 29.065 & $4.397,32$ & 6,61 & 10.661 & 13.203 & 44,7 \\
Breves & 92.860 & 99.080 & $9.562,24$ & 10,36 & 46.560 & 46.300 & 50,1 \\
Cachoeira do Arari & 20.443 & 22.786 & $3.100,26$ & 7,35 & 7.356 & 13.087 & 36 \\
Chaves & 21.005 & 22.821 & $13.084,76$ & 1,74 & 2.510 & 18.495 & 11,9 \\
Curralinho & 28.549 & 32.881 & $3.617,25$ & 9,09 & 10.930 & 17.619 & 38,3 \\
Gurupá & 29.062 & 32.049 & $8.540,11$ & 3,75 & 9.580 & 19.482 & 33 \\
Melgaço & 24.808 & 26.652 & $6.744,02$ & 3,95 & 5.503 & 19.305 & 22,2 \\
Muaná & 34.204 & 38.616 & $3.763,20$ & 10,26 & 14.521 & 19.683 & 42,5 \\
Ponta de Pedras & 25.999 & 29.700 & $3.363,66$ & 8,83 & 12.424 & 13.575 & 47,8 \\
Portel & 52.172 & 59.322 & $25.384,96$ & 2,34 & 24.852 & 27.320 & 47,6 \\
Salvaterra & 20.183 & 22.740 & $1.039,07$ & 21,88 & 12.672 & 7.511 & 62,8 \\
Santa Cruz do Arari & 8.155 & 9.635 & $1.076,65$ & 8,95 & 3.994 & 4.161 & 49 \\
São Sebastião da Boa Vista & 22.904 & 25.540 & $1.632,25$ & 15,65 & 9.902 & 13.002 & 43,2 \\
Soure & 23.001 & 24.488 & $3.517,32$ & 6,96 & 21.015 & 1.986 & 91,4 \\
\hline
\end{tabular}

1 - População total em 2010 (hab); 2 - População estimada para 2016 (hab); 3 - Área (km²); 4 - Densidade demográfica (hab/km²); 5 - População urbana em 2010 (hab); 6 - População rural em 2010 (hab); e 7 - Taxa de urbanização em 2010 (\%).

Fonte: IBGE (2010).

A densidade demográfica da região do Marajó apresentou certo crescimento quando comparado ao censo demográfico de 2000, no qual era de 3,65 habitantes $/ \mathrm{km}^{2}$, e atualmente é de 7,77 habitantes $/ \mathrm{km}^{2}$. No entanto, observa-se que a densidade demográfica nesses municípios é pequena, em razão da diminuta estrutura econômica implementada (BRASIL, 2007). Semelhantemente, verifica-se que essa situação condiz com uma dependência econômica em relação às atividades primárias realizadas nesta região, como a agricultura e o extrativismo.

A economia marajoara baseava-se da exploração de diversos artefatos naturais, especialmente da coleta da borracha, da castanha do Pará, do timbó, da madeira e da pesca. A agricultura era realizada como atividade somente para o uso da população local, ou seja, para sua subsistência. A dependência com relação à extração de recursos naturais seja de origem animal, vegetal ou mineral, estabeleceu o padrão de instalação dos habitantes da ilha, de tal maneira que a maior parte da população se dividiu por pequenos vilarejos, situado normalmente nos entroncamentos dos rios e igarapés (MDA, 2012).

As atividades econômicas da população ribeirinha são caracterizadas pela exploração de madeiras brancas (virola, pau mulato, sumaúma), do açaí (fruto e palmito), exploração da borracha, atividade pesqueira, cultivos agrícolas (milho, arroz, mandioca, melancia, etc.), direcionadas especialmente para o consumo familiar (MDA, 2012; VIVA MARAJÓ, 2011).

\section{RESULTADOS E DISCUSSÃO}

A taxa de urbanização dos municípios do Marajó é muito baixa, com cerca de $43,42 \%$ no ano de 2010 , ou menos da metade da média nacional, que no momento atual é de aproximadamente $84,6 \%$, onde a maioria da população brasileira reside em áreas urbanas, sendo esse cenário semelhante ao dos países desenvolvidos. Dos dezesseis municípios que fazem parte do território do Marajó, somente três (Breves, Soure e Salvaterra) tem população urbana superior à rural.

Como a maioria da população desses municípios residem na zona rural é essencial o fortalecimento de políticas públicas direcionadas ao campo e a agricultura familiar concatenadas com o desenvolvimento sustentável, objetivando-se o desenvolvimento de atividades agrícolas que possa garantir a geração de renda e que possibilite a existência de condições apropriadas para permanência do homem no campo, por meio da inclusão social, econômica e cultural.

A base econômica desses municípios é eminentemente agrícola, deste modo é fundamental a inserção de ações que possa qualificar os jovens e adultos que residem no campo, como também investir na transferência do conhecimento 
técnico para que o agricultor possa utilizar esse saber no desenvolvimento de suas atividades agrícolas. As famílias desta região apresentam dependência dos programas de transferência de renda como bolsa família e outros programas sociais, bem como das atividades extrativistas e agrícolas, no qual exerce uma forte influência no processo de formação e organização familiar desses habitantes (IBGE, 2010).

Atualmente, os descendentes da população de índios e negros, vivem em situação extremamente vulneráveis, no qual dependem de atividades extrativistas, roças e pesca para sua sustentação. Na região Amazônica, as políticas públicas direcionadas as populações caracterizadas como tradicionais são voltadas para os recursos naturais, visto que os habitantes dependem deles. Além disso, suas tecnologias, mesmo que sejam adaptadas a esses ambientes, de modo algum chega às condições de sofisticação das construídas pela sociedade (COELHO; MATHIS, 2005).

As modificações estruturais que aconteceu no aspecto socioeconômico e no meio ambiente no estado do Pará, no decorrer dos últimos anos, têm mudado a atuação relativa dos municípios no desenvolvimento e fortalecimento do crescimento econômico e das condições de progresso socioambiental do estado. O estado do Pará, desde antigamente, é visto como um produtor essencialmente extrativista e para que haja mudanças é necessário que ocorram fomentos das políticas públicas do governo estadual, para levá-lo a um sistema de economia de mercado e modernização a todos os municípios, o que ainda não é uma realidade praticada e bem partilhadas para todas as regiões, formando então, padrões de desenvolvimento e de concentração de renda altamente distintas nos municípios paraenses (NUNES et al., 2015).

A maior parte dos municípios do estado do Pará apresentam baixíssimas condições de sustentabilidade, entre esses municípios estão os localizados na mesorregião do Marajó, onde apresentam os piores níveis regionais do estado, não estando convergente com um desenvolvimento sustentável. Condição essa resultante do pequeno dinamismo da economia e de situações sociais precárias, constituindo-a, assim, como a mais vulnerável do estado. A região do Marajó tem permanecido praticamente na retaguarda das políticas públicas estaduais de desenvolvimento econômico, social e ambiental (NUNES et al., 2015).

Esse cenário tornou-se mais notório com a recente publicação do Índice de Desenvolvimento Humano Municipal (IDHM) dos 5570 municípios brasileiros pelo Programa das Nações Unidas para o Desenvolvimento (PNUD), no qual observou-se que todos os seis municípios que compõem a região marajoara polarizada por Breves encontram-se entre os 50 piores do Brasil, sendo que Melgaço $(0,481)$, foi classificado como o pior município do Brasil, os outros municípios que tiveram baixo desempenho foram Chaves $(0,453)$, Bagre $(0,471)$, Portel $(0,483)$, Anajás $(0,484)$ e Afuá $(0,489)$, conforme apresenta-se na Figura 2.

Figura 2. Espacialização do IDHM nos municípios do Arquipélago do Marajó, estado do Pará

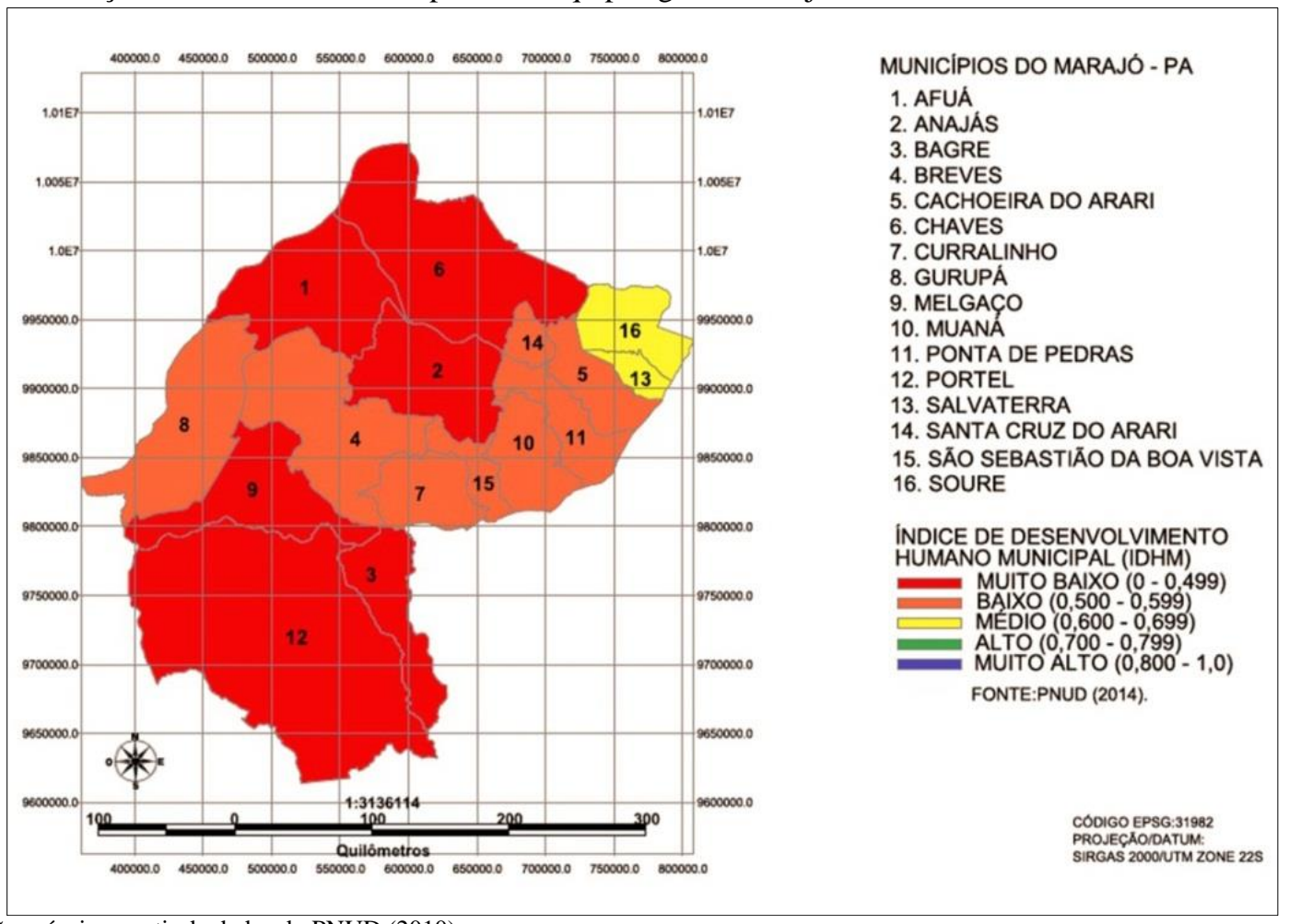

Fonte: Elaboração própria a partir de dados do PNUD (2010).

Dentre os principais elementos que contribuíram para que os 06 municípios da mesorregião apresentassem IDHM muito baixo, estão o baixo nível educacional e de renda da população. Por meio desses dados, observa-se que a forma e a estruturação de vida da população dos municípios do Marajó apresentam baixos padrões de qualidade de vida e de desenvolvimento econômico, constituindo-se em um cenário social de pobreza elevada, com altas taxas de analfabetismo e baixo acesso a educação (BEZERRA, 2014).

Diante desse cenário, os gestores municipais e o governo estadual têm na região do Marajó um enorme desafio, quanto à problemática da vulnerabilidade social e econômica, como também na ausência de serviços públicos como, por exemplo, os supracitados, constituindo-se em importantes elementos 
que colaboram para o decréscimo da qualidade de vida e para exaustão dos recursos naturais que, inevitavelmente afeta na dinâmica e na estrutura familiar desses habitantes, tornando esses lugares insustentáveis e insalubres.

Para modificar esse cenário de penúria os indivíduos desta região necessitam de novas formas de pensar, sentir e agir no ambiente em que estão inseridos. Portanto, é imprescindível uma mudança de concepção sobre a realidade local, buscando a experimentação de alternativas de produção apropriada com as condições naturais da região e respeitando a capacidade de suporte do meio natural. Porém, esse desafio não consiste em encontrar somente uma alternativa, mas muitas e distintas opções para diminuir as desigualdades e a pobreza, e desta maneira transformar o panorama da população marajoara, mostrando sua viabilidade e diversidade.

Uma possibilidade de esses municípios tentarem reverter essa situação de penúria seria por meio da geração de receita interna, buscando desenvolver a economia local através da produção de bens (duráveis e não duráveis), comercialização de mercadorias, turismo e prestação de serviços. No entanto, é essencial conhecer as potencialidades e aptidão econômica de cada município. Além disso, o governo do estado poderia cooperar por meio da formação de arranjos locais, reunindo municípios com vocações semelhantes.

$\mathrm{Na}$ Figura 3 apresenta-se a situação do índice de atendimento do serviço de coleta de esgoto doméstico, no qual por meio da última pesquisa do SNIS (2014) constatouse que a maioria dos municípios do Marajó não forneceu nenhuma informação a respeito da cobertura desse tipo de serviço, exceto o município de Chaves, em que $40 \%$ dos domicílios da zona urbana são atendidos com o serviço de coleta de esgoto. Na região Norte, somente $14,36 \%$ do esgoto recebe tratamento, e o índice de atendimento total é de aproximadamente $7,88 \%$, sendo a região com a pior situação no Brasil. Enquanto, que no estado do Pará o índice de coleta de esgoto é de $2,03 \%$ e o tratamento de esgoto é de aproximadamente $5,35 \%$.

Figura 3. Espacialização do índice de atendimento urbano por rede de esgoto nos municípios do Arquipélago do Marajó, estado do Pará

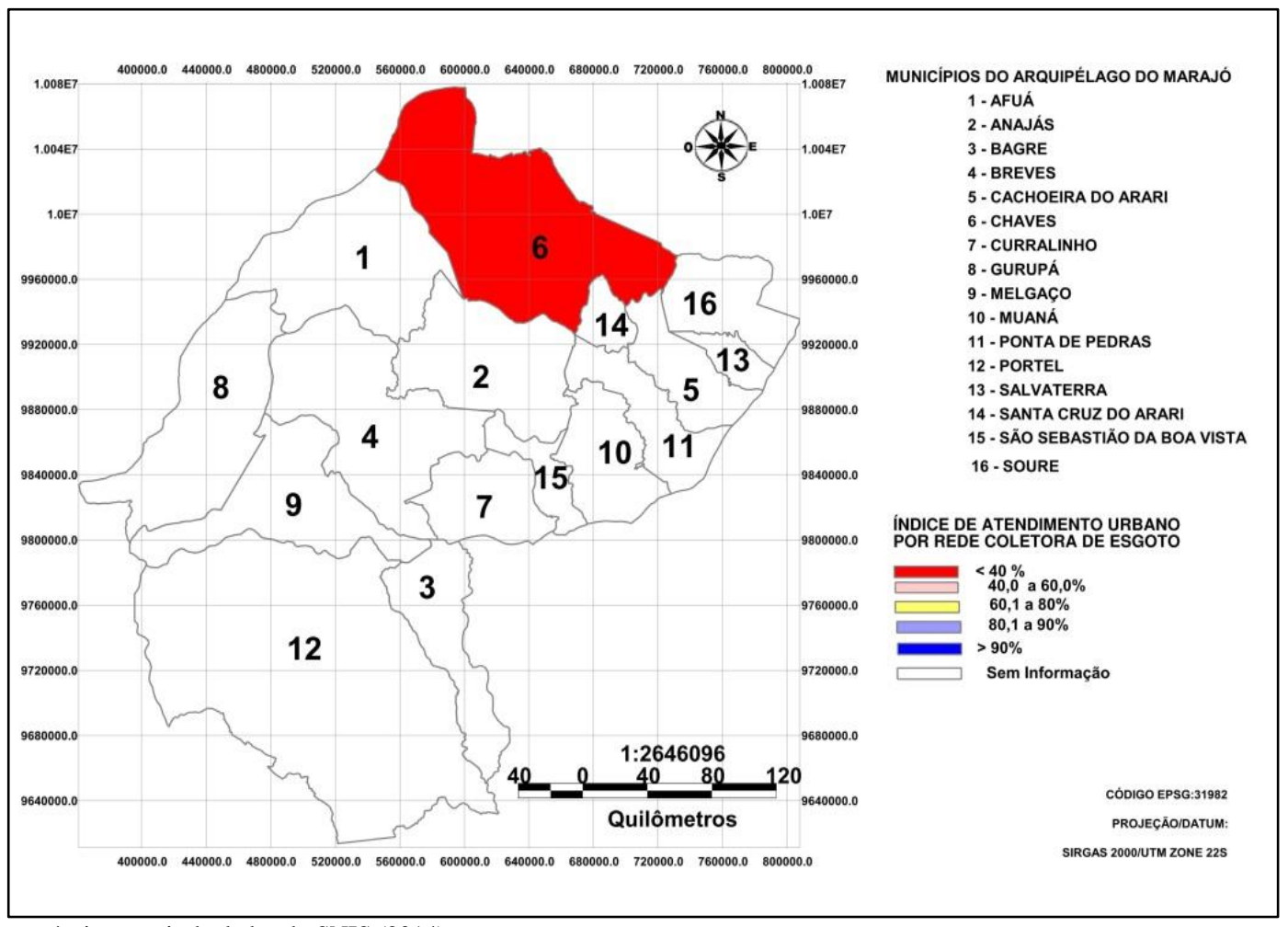

Fonte: Elaboração própria a partir de dados do SNIS (2014).

A conjuntura dos municípios da área de estudo quanto ao serviço supracitado reflete atual condição do país, onde a abrangência dos serviços de saneamento deixa a deseja, em particular com relação à coleta e ao tratamento do esgoto sanitário. Apesar do serviço de abastecimento de água ter se expandido nos municípios brasileiros, os índices de coleta e tratamento de esgoto sanitário são bem inferiores, com uma cobertura de $55 \%$ de coleta e $28 \%$ de tratamento de esgoto nos municípios, com base em informações do IBGE relacionadas ao ano de 2008 (IBGE, 2010). Segundo Moreira (2006) mais da metade das residências em áreas urbanas em que a renda das famílias varia cerca de meio e um salário mínimo não são assistido com nenhum serviço de esgotamento sanitário. Na Figura 4 mostra-se a porcentagem da população da área de estudo assistida com o serviço de coleta de resíduos sólidos domiciliares, no qual verifica-se um crescimento na coleta entre o período de 1991 até 2010. Atualmente, nenhum desses municípios tem uma coleta domiciliar abaixo de 55\%, no entanto apenas os municípios Afuá, Breves e Gurupá tem uma coleta maior que a média do estado do Pará, que é de aproximadamente 91,92\%. Porém, todos estão abaixo da média nacional que é de $97,02 \%$ para o ano de 2010. Contudo, espera-se que o serviço de coleta possa abranger uma maior cobertura da população nos próximos anos, visto que é a parte do gerenciamento dos resíduos sólidos mais sensíveis aos olhos da população, logo, a mais susceptível de crítica. 
Figura 4. Evolução da coleta de resíduos sólidos domiciliar nos municípios do Arquipélago do Marajó, estado do Pará

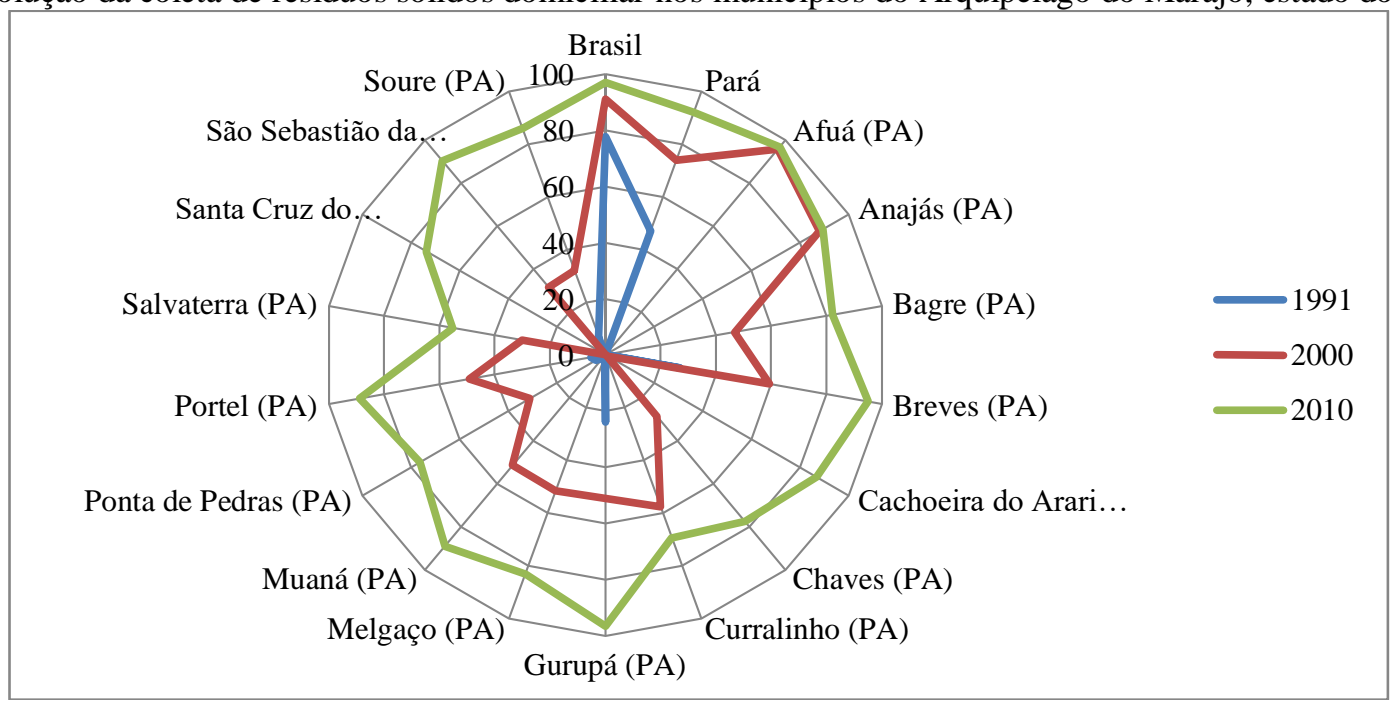

Fonte: Elaboração própria a partir de dados PNUD (2010).

Quando o poder público municipal não realiza o serviço de coleta de resíduos, a cidade fica com aspecto inóspito e com odor desagradável. Esse cenário pode causar desgaste político, diante disso algumas Prefeituras procuram promover investimentos na coleta de resíduos. Além disso, caso o município não remova os resíduos de origem domiciliar estará contribuindo para a proliferação de vetores transmissores de doenças, que encontram nos restos de alimentos que consumimos as condições propícias para se desenvolverem.
No tocante a destinação dos resíduos sólidos domiciliares, observa-se por meio de informações do SNIS (2014), que alguns municípios do Arquipélago do Marajó destinam seus RSD de uma maneira inapropriada, depositando-os diretamente no solo e a céu aberto (lixão), sem nenhuma norma de controle, enquanto que em outros municípios não existem nenhuma informação a respeito deste procedimento (Figura 5).

Figura 5. Espacialização dos tipos de unidades utilizadas para o manejo ou destinação dos RSD nos municípios do Arquipélago do Marajó, estado do Pará.

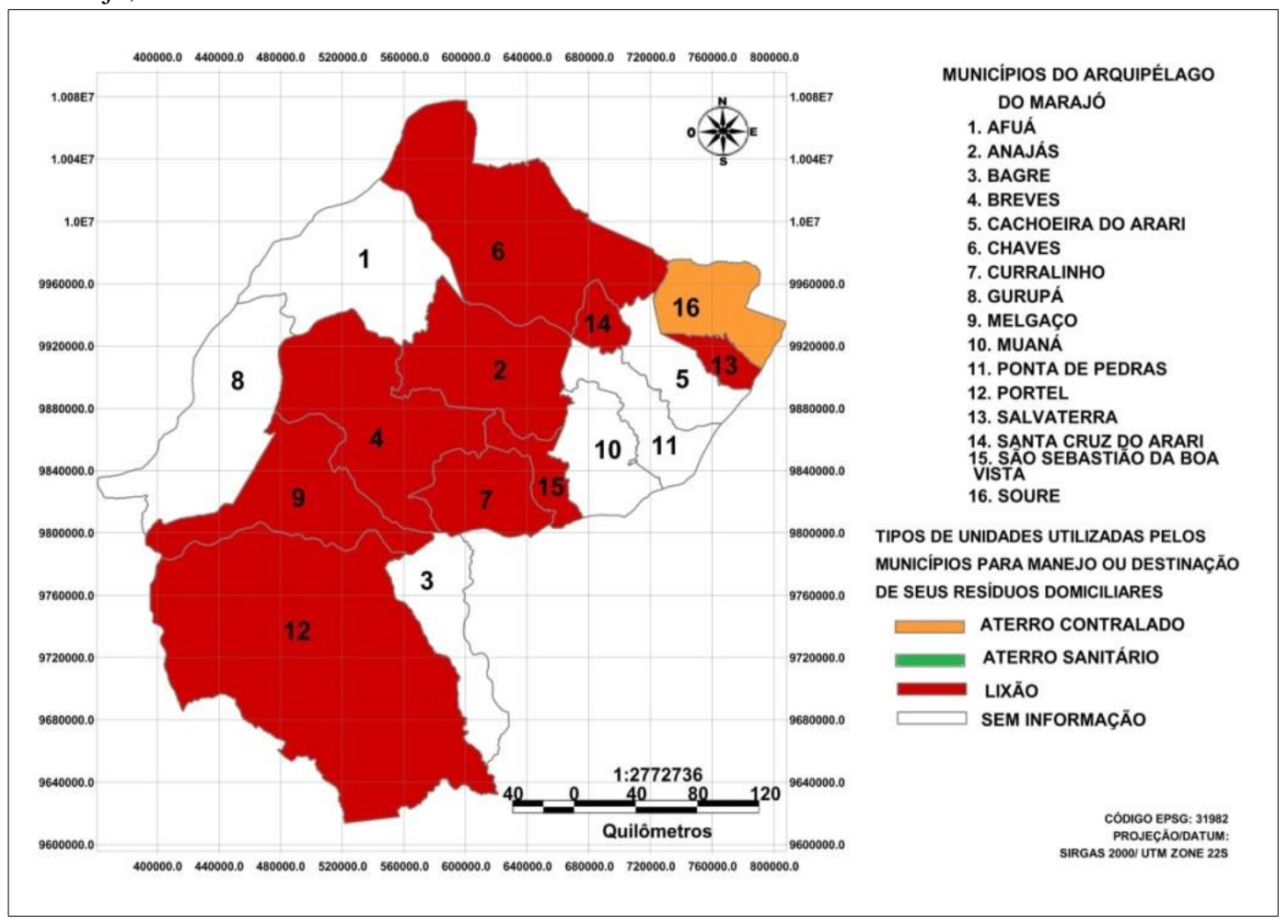

Fonte: Elaboração própria a partir de dados do SNIS (2014).

O manejo e a destinação inadequada dos resíduos concatenados com ausência de políticas públicas direcionadas a sua gestão, constitui-se atualmente em um problema relevante nas cidades brasileiras. Haja vista, que essa gestão inapropriada dos resíduos sólidos tem contribuído para surgimento de danos à saúde pública, e consequentemente, a 
qualidade de vida da população e a degradação do meio ambiente. Requerendo, portanto, de uma atenção especial por parte das autoridades públicas e da sociedade civil.

Vários municípios das regiões Norte e Nordeste apresentam deficiência na realização da gestão ambientalmente adequada dos resíduos sólidos domiciliares, possibilitando que práticas inapropriadas de disposição final se tornem corriqueira, como a deposição em vazadouros a céu aberto, área conhecida popularmente como lixão. A disposição inadequada dos RSD pode causar graves impactos ambientais, como a poluição do solo, da água, do ar e visual, odores desagradáveis, desvalorização de áreas vizinhas, proliferação e atração de micro e macro vetores que podem ser transmissores de doenças (CRISPIM et al., 2013).

Nos municípios das regiões supracitadas predomina a forma de disposição em lixões, com respectivamente $(85,5 \%)$ e $(89,3 \%)$. Para Rodrigues (2009) Essa forma de disposição predomina entre os municípios com orçamentos limitados, no qual os gestores municipais se preocupam apenas em afastar os resíduos do perímetro urbano, descartando-os nos lixões. Esse tipo de unidade utilizada para destinação final não se preocupa com medidas que visam à proteção do meio ambiente e a saúde pública. Além disso, não é utilizado nenhum critério técnico para escolha das áreas locacionais, tais como: proximidade de núcleos urbanos, permeabilidade do solo, profundidade do lençol freático, isolamento visual da vizinhança, etc.
De acordo com Lei 12.305, de 02 de agosto de 2010, que Institui a Política Nacional de Resíduos Sólidos (PNRS), decreta no art. 47, inciso II, a proibição do lançamento de resíduos sólidos in natura a céu aberto, excetuado os resíduos de mineração. Com base na Lei supracitada, verifica-se que os municípios da área de estudo não enquadram-se dentro dessa regulamentação, necessitando encontrar uma forma de disposição final que seja ambientalmente adequada. Entre as opções que podem ser utilizadas para destinação e tratamento dos resíduos domiciliares destacam-se os aterros sanitários, a reutilização, a reciclagem, a compostagem, a recuperação e o reaproveitamento energético (BRASIL, 2010).

No tocante ao acesso ao serviço de atendimento urbano por rede de água, verificou-se que o índice médio dos municípios de Anajás, Cachoeira do Arari, Curralinho, Salvaterra e Portel é menor que $40 \%$, conforme apresentado na Figura 6, ficando abaixo da média do estado que é de aproximadamente $45,33 \%$ (TRATA BRASIL, 2013). Enquanto, que na faixa de $40 \%$ a $60 \%$, aparecem os municípios de Afuá e Breves. O desempenho destes municípios é semelhante ao obtido pelos estados do Acre, Pará e Rondônia, que ficaram na penúltima faixa em uma pesquisa de escala nacional, com $40 \%$ a $60 \%$. Na faixa de $80 \%$ a $90 \%$, aparecem outros 2 municípios, Chaves e Soure, na faixa maior que 90\%, somente Santa Cruz do Arari (SNIS, 2014).

Figura 6. Espacialização do índice de atendimento urbano por rede de água nos municípios do Arquipélago do Marajó, estado do Pará

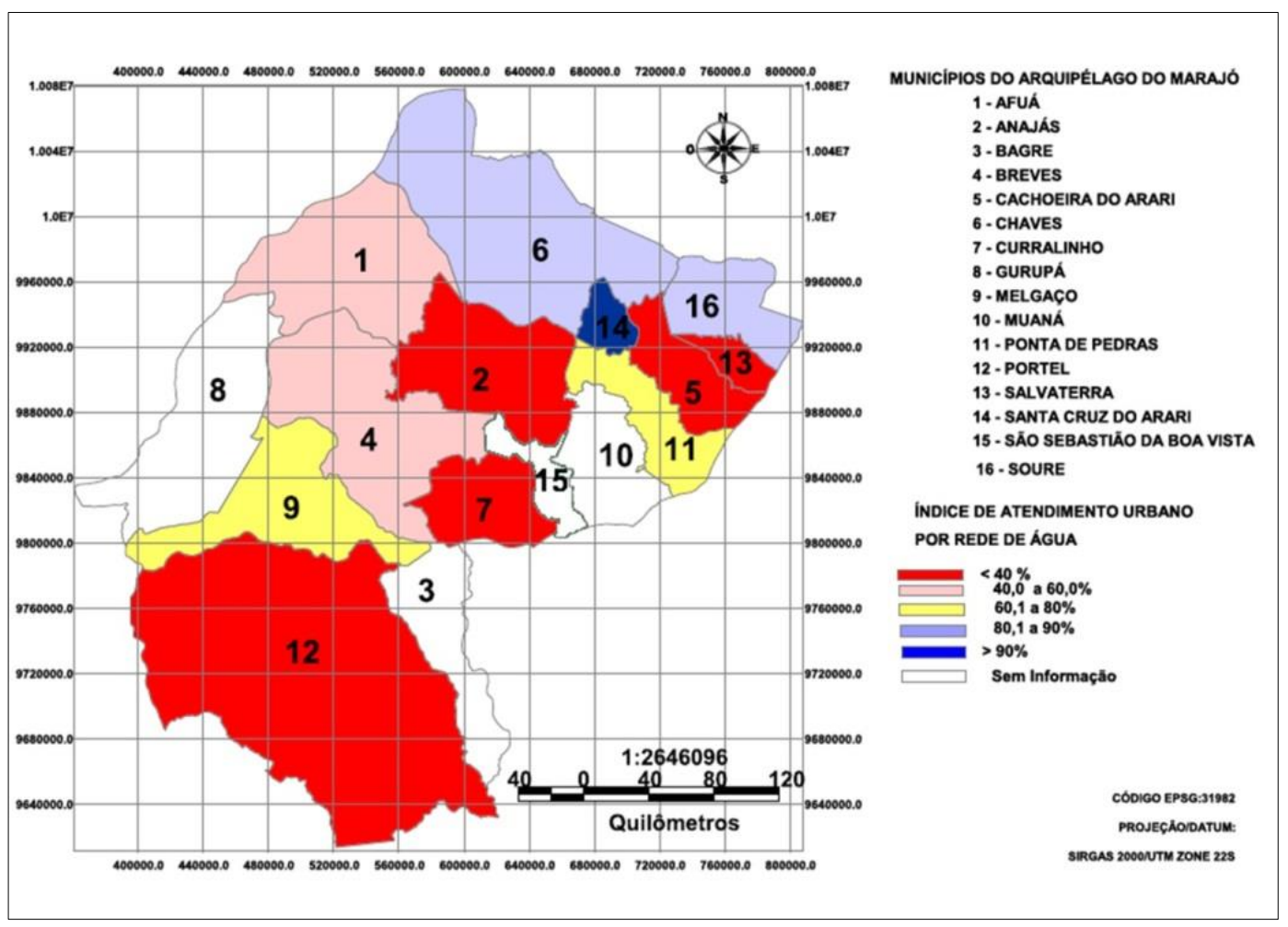

Fonte: Elaboração própria a partir de dados do SNIS (2014).

Embora, o acesso regular a água potável e segura, seja um direito humano básico, verifica-se por meio dessas informações que uma parcela dos habitantes dos municípios do arquipélago do Marajó - PA não dispõe do serviço de abastecimento de água por rede geral, tornando-se algo preocupante, pois induz a busca de agua em fontes alternativas, de qualidade sanitária duvidosa ou que não apresentam condições aceitáveis de qualidade, podendo ocasionar doenças de veiculação hídrica à população, causando custos com internações hospitalares, exames e medicamentos. 
A expansão do serviço de fornecimento de água por meio de rede geral para os habitantes desses municípios deve ser uma das ações prioritária nas politicas públicas a ser realizada pelos gestores municipais e pelo governo estadual. Pois, o acesso à água potável é um serviço básico essencial para população, levando em consideração que é um setor estratégico para melhorar a qualidade de vida e a saúde da população, tendo implicações na redução da mortalidade infantil, diminuição de doenças infecciosas de veiculação hídrica, reduzir custos sanitários e no meio ambiente.

No que concerne às perdas de água nos sistemas de abastecimento de água (Figura 7), verifica-se que os municípios de Melgaço e Chaves têm perda maior que 90\%, enquanto Curralinho fica entre 80,1 a $90 \%$, e os demais municípios apresentam perdas inferiores a $40 \%$, e alguns não possuem nenhuma informação. $\mathrm{O}$ desempenho desses municípios em relação a perdas de água está acima da média nacional que é aproximadamente $37 \%$, quando relacionado com o desempenho de países como Alemanha e o Japão, essa diferença é considerável, haja vista que esses países conseguiram diminuir suas perdas para cerca de $10 \%$, ao mesmo tempo em que países como a Austrália e Nova Zelândia conseguiram reduzir suas perdas menores que $10 \%$ (SNIS, 2014).

Figura 7. Espacialização das perdas de água no sistema de abastecimento nos municípios do Arquipélago do Marajó, estado do Pará

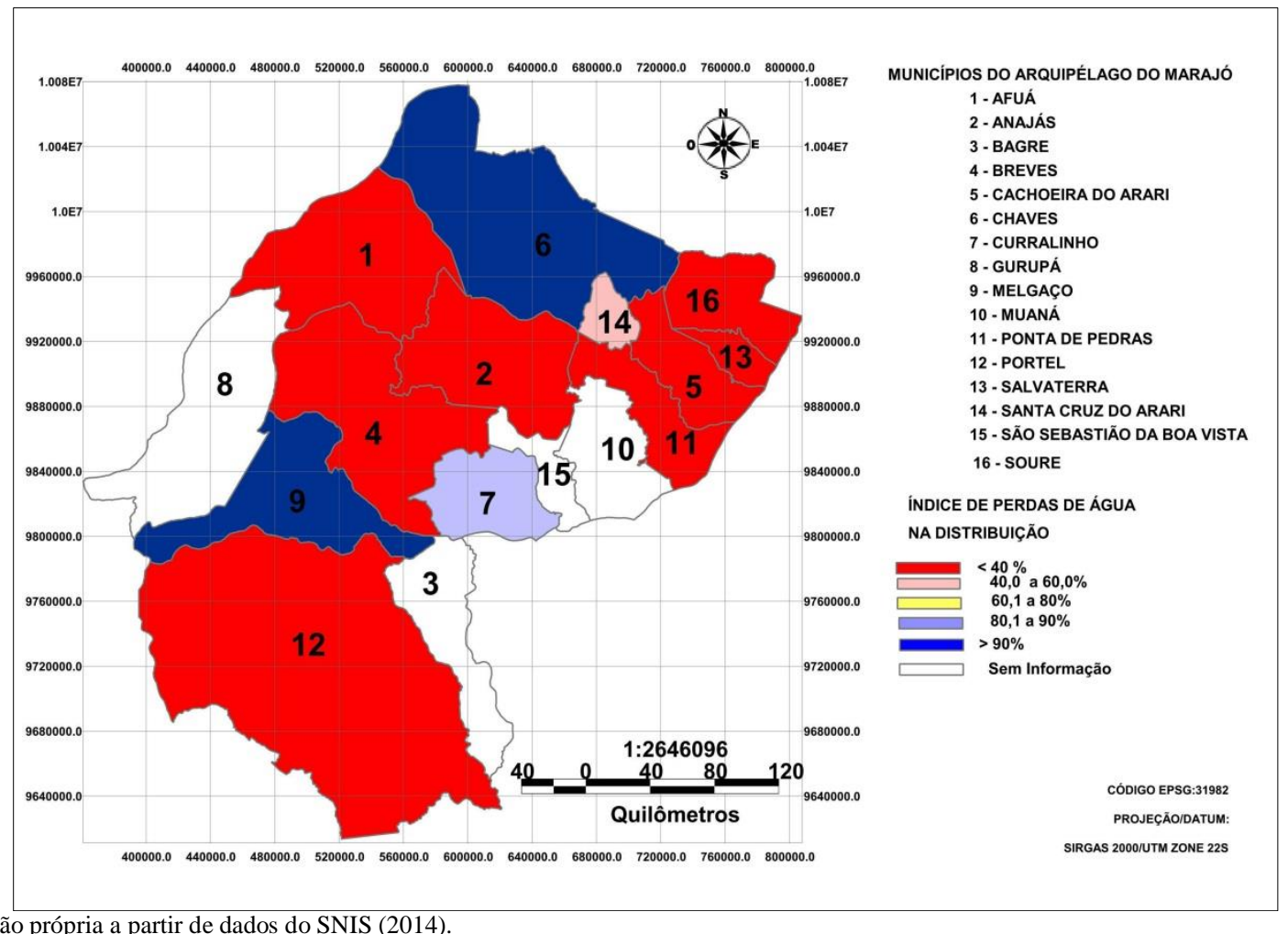

Fonte: Elaboração própria a partir de dados do SNIS (2014).

Com base nesses dados, constata-se que os sistemas de abastecimento de água dos municípios pesquisados apresentam perdas elevadas, ocasionando desperdício de recursos naturais, operacionais e de receita para as concessionárias que prestam esse serviço. Além disso, as perdas de água não prejudicam apenas na distribuição da própria, mas também na ampliação do esgotamento sanitário, tornando-se um desafio muito relevante aos administradores, haja vista a imprescindibilidade de diminuir as formas de desperdício da água, objetivando-se uma utilização de maneira sustentável (MARINHO; NASCIMENTO, 2014). Em relação aos fatores que estejam contribuindo para o desperdício de água nos sistemas de abastecimento podem estar relacionados a problemas estruturais, operacionais e culturais.

\section{CONCLUSÃO}

Dos resultados obtidos nesta pesquisa, destaca-se a presença de aspectos relevantes na caracterização da situação do saneamento ambiental dos municípios do Marajó, como por exemplo, o baixo índice de atendimento do serviço de coleta de esgoto doméstico, a predominância de lixões para deposição dos resíduos sólidos domiciliares e o baixo índice de desenvolvimento humano municipal (IDHM). Além disso, percebe-se que a disponibilidade de informações nessas bases de dados dos órgãos e entidades é fundamental para a análise da condição sanitária, bem como para auxiliar na determinação de prioridades nas ações do poder público e sociedade civil direcionada aos serviços de saneamento básico.

A construção de novas possibilidades de desenvolvimento nesta região deve estar articulada como medidas de educação e gestão ambiental sustentável, concatenada as iniciativas sociais que resultem em melhoria das condições de vida, objetivando-se alcançar não um, mas muitos e diversos caminhos para diminuir as desigualdades e a pobreza, buscando uma modificação na característica Marajoara, apresentando sua viabilidade e diversidade econômica. 


\section{REFERÊNCIAS}

BEZERRA, M. M. Desenvolvimento Institucional da Educação Superior no Marajó: um estudo sobre a implementação dos programas REUNI, PARFOR UAB e PROUNI no município de Breves (PA), no período de 2009 a 2013. 2014. 95f. Dissertação (Mestrado) - Universidade Federal do Pará, Núcleo de Altos Estudos Amazônicos, Programa de Pós-Graduação em Gestão Pública para o Desenvolvimento, Belém, 2014.

\section{BRASIL. GOVERNO DO ESTADO DO PARÁ; GOVERNO}

FEDERAL. Plano de Desenvolvimento Territorial Sustentável do Arquipélago do Marajó. 2007. 313p. Disponível em <http ://bvsms. saude.gov.br/bvs/ publicações /plano_desenv_arquipelago_marajo.pdf $\rangle$. Acesso em: 27 maio 2016.

BRASIL. Departamento Nacional de Produção Mineral. Projeto Radam folha SA. 22 Belém: geologia, geomorfologia, solos, vegetação e uso potencial da terra. Rio de Janeiro, 1974.

BRASIL. Lei de $\mathrm{N}^{\circ} 12.305$, de 2 de agosto de 2010. Institui a Política Nacional de Resíduos Sólidos; altera a Lei no 9.605, de 12 de fevereiro de 1998; e dá outras providências. Disponível em: <http:// www.planalto.gov.br/ ccivil_03/ _ato2007-2010/2010/lei/112305.htm>. Acesso em: 24 maio. 2016.

COELHO, M. C. N.; MATHIAS, A. Políticas públicas e desenvolvimento local na Amazônia: uma agenda de debate. Belém: UFPA/NAEA, 2005. 211p.

CRISPIM, D. L.; ANDRADE, S. O. de.; MENESES, J. A. DIAS. de.; CHAVES, A. D. C. G.; BORGES, M. da G. B. Impactos ambientais decorrentes do uso e ocupação desordenada do espaço urbano: um estudo de caso da cidade de Baixio/CE. Revista Verde de Agroecologia e Desenvolvimento Sustentável, v 9. , n. 4 , p. 44 - 49, out-dez, 2014. Disponível em: $<$ http://www.gvaa.com. br/revista/index.php/RVADS/article/view/2998>. Acesso em: 01 maio 2016

CRISPIM, D. L.; CHAVES, A. D. C. G.; ALMEIDA, R. R. P. de.; FREITAS, A. J. F. de.; FERREIRA, A. C. Saneamento Básico: uma questão de qualidade ambiental na cidade de Pombal - PB. Revista Brasileira de Gestão Ambiental (RBGA), v. 7, n.3, p. 20 - 27, 2013. Disponível em:< http://www.gvaa.com.br/revista/Index.php/RB

GA/article/view/2536/2133>. Acesso em: 02 jun. 2016.

EBRAHIMZADEH, I.; AZIZ SHAHRAKI, A.; AKBAR SHAHNAZ, A.; MYANDOAB, A. M. Progressing urban development and life quality simultaneously. City, Culture and Society, v. 7, p. 186-193, 2016 http://dx.doi.org/10.1016/j.ccs.2016.03.001

FERRER, A. L. C.; THOMÉ, A. M. T.; SCAVARDA, A. J. Sustainable urban infrastructure: A review. Resources, Conservation and Recycling. (2016), http://dx.doi.org/10.1016/j.resconrec.2016.07.017
IBGE. Instituto Brasileiro de Geografia e Estatística. Censo Demográfico 2010. Rio de Janeiro: IBGE, 2010. Disponível em: <http://www.cidades.ibge.gov.br/xtras/temas. phpphp?lang $=\&$ codmun $=150450 \&$ idtema $=16 \&$ search $=$ para melgaco|sintesedasinformacoes〉. Acesso em: 19 maio 2016.

JANA, A.; HARATA, N. Provisioning health care infrastructure in communities: Empirical evidences from West Bengal, India. Socio-Economic Planning Sciences, v. 54 , p. 37-46, 2016. http://dx.doi.org/10.1016/j.seps. 2016.02.003

LI, F.; LIU, X.; ZHANG, X.; ZHAO, D.; LIU, H.; ZHOU, C.; WANG, R. Urban ecological infrastructure: an integrated network for ecosystem services and sustainable urban systems. Journal of Cleaner Production, (2016), http://dx.doi.org/10.1016/j.jclepro.2016.02.079

LIMA, C. M. de. Dinâmica da vegetação e inferências climáticas no Quaternário Tardio na região da Ilha de Marajó (PA), empregando os isótopos do carbono $(12 \mathrm{C}, 13 \mathrm{C}, 14 \mathrm{C}) \mathrm{da}$ matéria orgânica de solos e sedimentos. 2008. 182f. Dissertação (Mestrado) - Centro de Energia Nuclear na Agricultura, Universidade de São Paulo, Piracicaba, 2008.

LOURENÇO JUNIOR, J. de B.; GARCIA, A. R. Panorama da bubalinocultura na Amazônia. In: ENCONTRO INTERNACIONAL DA PECUÁRIA DA AMAZÔNIA, 1. 2008, Belém, PA. Anais... Belém, PA: FAEPA; Instituto Frutal; SEBRAE-PA, 2008. Disponível em:<http://www.alice.cnptia.embrapa.br/handle/doc/409969. Acesso em: 28 maio 2016.

MARINHO, I. M. R. de S.; NASCIMENTO, I. G. do. Avaliação do saneamento urbano de Macapá através do índice de qualidade do saneamento ambiental. 2014. 61f. Monografia (Graduação em Ciências Ambientais) Departamento de Meio Ambiente e Desenvolvimento, Universidade Federal do Amapá, Amapá, 2014.

MDA. Ministério do Desenvolvimento Agrário. Relatório Analítico do Território do Marajó. Belém, 2012. 79p. Disponível em:<http://sit.mda.gov.br/dowload/ra/ra129.pd f.>. Acesso em: 20 maio 2016.

MOREIRA, M. A. R. G. Potencial de mercado de eficiência energética no setor de água e esgoto no Brasil: avaliação de estratégias segundo o modelo de Porter. 2006. 280 f. Dissertação (Mestrado em Ciências: Planejamento Energético) - Faculdade de Engenharia, Universidade Federal do Rio de Janeiro, Rio de Janeiro, 2006.

NASCIMENTO, E. C. do.; CRUZ, B. E. V. da.; CALVIS, M. F.; CARVALHO, J. P. L.; REIS, C. dos.; GOMES, D. L. A influência do Programa Bolsa Família nas práticas alimentares das famílias do Território do Marajó, Pará, Brasil. Revista Scientia Plena, v.12, n.6, p. 1-11, 2016. Disponível em: $<$ https://www.scientiaplena.org.br/sp/article/view/3110/ 1492>. Acesso em: 02 set. 2016. 
PRODANOV, C. C.; FREITAS, E. C. de. Metodologia do trabalho científico: métodos e técnicas da pesquisa e do trabalho acadêmico. 2. ed. Novo Hamburgo: Feevale, 2013.

PNUD. Programa das Nações Unidas para o Desenvolvimento. Ranking IDHM Municípios 2010. 2010. Disponível em:< http://www.pnud.org.br/atlas/ranking/Rank ing-IDHM-Municipios-2010.aspx>. Acesso em: 02 maio 2016.

REIS, S.; MORRIS, G.; FLEMING, L. E.; BECK, S.; TAYLOR, T.; WHITE, M.; DEPLEDGE, M. H.; STEINLE, S.; SABEL, C. E.; COWIE, H.; HURLEY, F.; DICK, J. MCP.; SMITH, R. I.; AUSTEN, M. Integrating health and environmental impact analysis. Public health, v. 129, p. 13831389, 2015.

RODRIGUES, C. dos S. Gerenciamento integrado de resíduos sólidos urbanos: desafios, possibilidades e limitações para implantação no município de Imbituba, SC. 2009. 154f. Monografia (Graduação em Engenharia Ambiental) Universidade do Extremo Sul Catarinense - UNESC, Criciúma, 2009.

SILVA, F. C. da.; AMIN, M. M.; NUNES, S. F. Sustentabilidade dos municípios da Amazônia. Belém: NAEA, 2015. 458p.

SNIS. SISTEMA NACIONAL DE INFORMAÇÕES SOBRE SANEAMENTO. Diagnóstico do Manejo de Resíduos Sólidos Urbanos - 2014. Brasília: MCIDADES.SNSA, 2014. 154p. Disponível em: < http://www.snis.gov.br/diagnosticoresiduos-solidos/diagnostico-rs-2014>. Acesso em: 24 maio 2016.

SNSA. Sistema Nacional de Informações sobre Saneamento: Diagnóstico dos Serviços de Água e Esgotos - 2014. Brasília: SNSA/MCIDADES, 2016. 212 p.

TRATA BRASIL. Situação Saneamento no Brasil. 2013. Disponível em: < http://www.tratabrasil.org.br/sanea mentono-brasil >. Acesso em: 03 jun. 2016.

VIVA MARAJÓ. Diagnóstico Socioeconômico, Ambiental e Cultural do Arquipélago do Marajó. 2011. 103p. Disponível em: < https://institutopeabiru.files.ordpress.com./2

012/09/vivamarajo-escutamarajo.pdf $>$. Acesso em: 25 maio 2016. 